\title{
A UTILIZAÇÃO DAS TECNOLOGIAS DIGITAIS NO DESENVOLVIMENTO DAS COMPETÊNCIAS COMUNICATIVAS EM FRANCÊS
}

\section{THE USE OF DIGITAL TECHNOLOGIES IN THE DEVELOPMENT OF FRENCH COMMUNICATION SKILLS}

\author{
Stella Maria Peixoto de Azevedo Pedrosa ${ }^{1}$, Diva Maria Pimentel Rocha ${ }^{2}$
}

\begin{abstract}
RESUMO: O objetivo do artigo é apresentar parte dos resultados de uma pesquisa-ação que teve como foco o desenvolvimento das competências comunicativas em francês, a partir da utilização das Tecnologias de Informação e Comunicação (TIC), por estudantes do Ensino Médio de uma escola pública federal da cidade do Rio de Janeiro. A base da proposta foi a incorporação do uso das tecnologias digitais - sobretudo a partir do tablet oferecido pela escola e do smartphone pessoal dos estudantes - à Abordagem Comunicativa de ensino de francês, sob a perspectiva acional preconizada pelo Quadro Europeu Comum de Referência para Línguas (QECRL). As atividades desenvolvidas, ao longo de um ano letivo, em conjunto com os dezesseis participantes, de quinze a dezessete anos de idade, foram realizadas no âmbito do projeto DELF - Diploma de Estudos de Língua Francesa, visando à preparação para os exames do nível A2.
\end{abstract}

PALAVRAS-CHAVE: ensino de língua estrangeira; pesquisa-ação; recursos digitais; tecnologias de informação e comunicação em educação.

ABSTRACT: The objective of the article is to present part of the results of an action research that focused on the development of French communicative skills, from the use of Information and Communication Technologies (ICT), by high school students from a federal public school of the city of Rio de Janeiro. The basis of the proposal was the incorporation of the use of digital technologies - mainly from the tablet offered by the school and the students' personal smartphone - to the Communicative Approach to teaching French, under the action perspective recommended by the Common European Framework of Reference for Languages (CECRL). The activities carried out, over the course of an academic year, together with the sixteen participants, aged between fifteen and seventeen years old, were carried out within the scope of the DELF project - Diploma in French Language Studies, aiming at the preparation for the A2 level exams.

KEYWORDS: foreign language teaching; action research; language digital resources; information and communication technologies in education.

\section{Introdução}

\footnotetext{
${ }^{1}$ Programa de Pós Graduação em Educação (PPGE), Universidade Estácio de Sá.

${ }^{2}$ Mestre em Educação pela Universidade Estácio de Sá.
} 
O ensino-aprendizagem de línguas estrangeiras na escola pública, como mostram os Parâmetros Curriculares Nacionais (BRASIL, 1998), amplia as possibilidades do agir social e o desenvolvimento integral do indivíduo, pois proporciona uma abertura tanto para o conhecimento e a compreensão do mundo próximo, quanto de outras culturas mais distantes. As habilidades comunicativas, em mais de uma língua, são fundamentais para a inserção das pessoas na sociedade atual, lhes garantindo acesso mais igualitário ao mundo acadêmico, do trabalho e da tecnologia, preconizam os PCNs.

A incorporação das TIC na educação possibilita a transformação e a melhora dos processos educacionais, não de forma automática, porém modificando o contexto desses processos em que as relações entre os atores, as tarefas e os conteúdos de aprendizagem abrem "o caminho para uma eventual transformação profunda desses processos, que ocorrerá, ou não, e que representará, ou não, uma melhora efetiva, sempre em função dos usos concretos que se dê à tecnologia" (COLL; MONEREO, 2010, p. 11).

Em relação ao uso das TIC, dentre outros autores, nos fundamentamos em Lévy (1999). Ele afirma que a técnica não contém a "salvação" para todos os problemas, tampouco tem unicamente o poder de "perdição" e enfatiza que "os instrumentos que construímos nos dão poderes, mas coletivamente responsáveis, a escolha está em nossas mãos” (LÉVY, 1999, p. 17). Além disso, consideramos que as TIC podem auxiliar na construção de novos saberes e práticas, e a escola tem o desafio de "viabilizar-se como espaço crítico em relação ao uso e à apropriação dessas tecnologias de comunicação e informação" (KENSKI, 2012, p. 25).

Integrar as TIC às práticas educativas requer planejamento e reflexão sobre a ação docente e discente, sendo necessário reunir "os benefícios, riscos e desafios do uso da tecnologia nestes ambientes, permeando os conteúdos, as estratégias de ensino e as implicações educativas e sociais" (ARAÚJO; FARIA; PEDROSA, 2014, p. 1). Após um levantamento de artigos, dissertações e teses que tratassem do assunto, decidimos realizar uma pesquisa-ação apoiada na "reflexão-sobre-a-ação" (SCHÖN, 2000).

A autora dos levantamentos, professora de francês da rede pública federal de ensino básico, participou diretamente desta pesquisa-ação. Neste artigo, identifica-se como professora/pesquisadora. As tecnologias digitais móveis foram integradas às atividades de ensino e aprendizagem, dentro e fora da sala de aula, com o objetivo de desenvolver 
competências de comunicação em francês. Adiante, serão detalhados o foco, o design, o campo, os participantes, a metodologia, bem como os autores teóricos, que embasam este estudo, e os resultados alcançados. Tudo isto de acordo com o recorte da pesquisa trazido neste artigo.

Apresentaremos este trabalho em três seções: (1) Percurso da pesquisa; (2) Desenvolvimento das competências comunicativas em francês; e (3) Considerações finais. Almejamos assim oferecer dados que poderão ser discutidos e completados por outros pesquisadores.

\section{Percurso da pesquisa}

A revisão da literatura, como propõe Alves-Mazzotti (2001), foi feita a partir do estudo do tema principal: o uso das Tecnologias de Informação e Comunicação nos processos educacionais, incluindo relatos de pesquisas e teorias utilizadas para explicar o conhecimento já construído. Em especial, os estudos destacados abaixo, suscitaram nosso interesse em desenvolver a investigação.

A dissertação de Alcântara (2006), apresenta uma plataforma para cursos online, desenvolvida para a realização de atividades complementares, fora da sala de aula, por alunos do curso presencial de Letras (Português-Francês) de uma universidade pública paulista. Os resultados evidenciaram o aumento da interação entre alunos e professores e maior autonomia dos estudantes. Por iniciativa própria, os alunos indicaram, nos meios disponibilizados, diversos sites, voltados para seus interesses, que passaram a visitar para aprender mais o idioma por meio de leituras, música, etc.

Um estudo de caso no Ensino Fundamental, apresentado na dissertação de Frango (2012), teve como objetivo avaliar o desenvolvimento da competência da oralidade em francês de onze alunos, a partir do uso das TICs, em uma escola pública de Portugal. Foi observado que os recursos utilizados (YouTube, trechos de filmes, clipes musicais, por exemplo) favoreceram o desenvolvimento da oralidade, pois promovem a expressão oral em francês.

Galli e Macedo (2014) fazem uma análise qualitativa de um material didático, mostrando as vantagens e benefícios da utilização das TIC na aprendizagem de francês. Ao final de cada uma das três unidades do livro, endereços eletrônicos de origem francesa são 
apresentados para que o aluno visite dois museus, dois jornais, um sítio de poesias, uma rádio e uma TV. O objetivo é trabalhar aspectos culturais e linguísticos. As autoras inferem que os recursos tecnológicos, integrados às atividades de aprendizagem, podem aumentar o conhecimento em francês e aprimorar o desenvolvimento do letramento digital do aluno. Contudo, não foram apresentados dados empíricos na conclusão dessa pesquisa.

Visando buscar outros dados e desenvolver outros achados, esta pesquisa inscreveu-se na perspectiva qualitativa cujo foco e design emergem de "um processo de indução, do conhecimento do contexto e das múltiplas realidades construídas pelos participantes em suas influências recíprocas" (ALVES-MAZOTTI, 2000, p. 146).

Aprofundamos as questões que envolvem a pesquisa-ação educacional, baseando-nos nas ideias de Tripp (2005). O autor destaca que esse tipo de investigação é a estratégia apropriada para que professores/pesquisadores aprimorem tanto seu ensino quanto o aprendizado de seus alunos.

Além disto, observar, reexaminar e analisar as próprias experiências traz à tona problemas pedagógicos que mostram os pontos discrepantes entre o real e o ideal, entre a intenção e a ação e ainda entre a ação e o efeito (MOREIRA e CALEFFE, 2008). Isso favorece a pesquisa e a busca de novas estratégias que levem a mudanças qualitativas. Questionar a própria prática é um processo de aprendizagem que pode levar à modificação do fazer docente.

Desenvolvemos uma pesquisa-ação prática, em uma escola pública federal de educação básica na cidade do Rio de Janeiro. Os participantes da pesquisa: dezesseis estudantes do Ensino Médio, entre quinze e dezessete anos de idade e a professora/pesquisadora.

Esses alunos começaram o aprendizado de francês no $5^{\circ}$ ano do Ensino Fundamental, naquela instituição pública de ensino. No período de realização dessa pesquisa-ação, os estudantes tinham três tempos de aulas regulares de francês, em dois dias distintos, no turno da tarde, com outro professor. Uma vez por semana, no turno da manhã, esses dezesseis jovens participavam, voluntariamente, de dois tempos de aulas do projeto DELF Scolaire, nível A2, com a professora/pesquisadora.

Com o objetivo de aprofundar as competências de compreensão e de produção orais na língua francesa, as aulas do referido projeto complementam o trabalho desenvolvido nas aulas 
regulares. Os estudantes desenvolvem habilidades e competências de comunicação, preparando-se para as provas que acontecem ao final de cada ano letivo. Uma instituição particular de ensino de francês é responsável pela organização geral dos exames $D E L F$ no Rio de Janeiro. A referida escola pública federal, além de outras instituições de ensino público e privado trabalham em parceria e mantêm um convênio com aquele estabelecimento particular. No contexto geral da pesquisa, a metodologia inclui a proposta de uso das tecnologias digitais nas aulas e em casa para: pesquisas na Internet; produções de áudios com o uso do smartphone; elaboração e edição de textos por meio do Google Drive ${ }^{3}$; desenvolvimento de trabalho em grupo com uso do Power Point; download e organização de arquivos para produções escritas e orais; compartilhamento de arquivos, links e imagens pelas redes sociais virtuais.

Para o levantamento de dados, aplicamos um questionário com respostas fechadas e abertas sobre a utilização das tecnologias digitais nas atividades do cotidiano escolar; a professora/pesquisadora lançou mão da observação durante as aulas e de entrevistas individuais semiestruturadas.

Aqui ressaltamos a importância da coleta de dados nas entrevistas para aprofundamento das questões não levantadas no questionário ou na observação da professora/pesquisadora. A pesquisa-ação é um dos incontáveis "tipos de investigação-ação, que é um termo genérico para qualquer processo que siga um ciclo no qual se aprimora a prática pela oscilação sistemática entre agir no campo da prática e investigar a respeito dela" (TRIPP, 2005, p. 446).

A análise de dados foi guiada com apoio em concepções de Bardin (1977). Procedemos a três etapas: (1) pré-análise; (2) exploração do material; (3) tratamento dos resultados e interpretação. Ao final, o material foi organizado em quatro conjuntos: (1) $O$ uso dos dispositivos digitais (computador, notebook, tablet e smartphone); (2) o uso das redes sociais digitais (e-mail, Facebook, Twitter e WhatsApp); (3) as atividades realizadas por meio das tecnologias digitais relacionadas ao desenvolvimento das habilidades de pensamento, segundo a Taxonomia de Bloom para a era digital, de Churches (2009); (4) as possibilidades de desenvolvimento das competências comunicativas em francês, preconizadas pelo Cadre

\footnotetext{
${ }^{3}$ Serviço virtual de armazenamento e sincronização de arquivos, que abriga e oferece possibilidade de compartilhamento para edição de documentos, planilhas, apresentações, etc.
} 
européen commun de référence pour les langues (CONSEIL DE L'EUROPE, 2001) a partir do uso do tablet oferecido pela escola e do smartphone, além dos demais dispositivos digitais de que dispunham os estudantes. Esse último conjunto é o foco do presente artigo.

\section{Desenvolvimento das competências comunicativas em francês}

As atividades do projeto $D E L F$, voltadas para a compreensão e a produção escritas e orais, tiveram por base a abordagem sob a perspectiva acional ancorada no Cadre européen commun de référence pour les langues (CONSEIL DE L'EUROPE, 2001) ${ }^{4}$. A perspectiva acional visa aprofundar os aspectos pragmáticos (uso da língua para a interação social) e os aspectos sociolinguísticos (uso da língua em diferentes contextos) do idioma em estudo.

O Cadre, como o documento é comumente referido, fornece uma base comum para a elaboração de programas de ensino-aprendizagem de línguas, linhas de orientação curriculares, exames, manuais, etc. A descrição abrange também o contexto cultural dessa mesma língua e define, ainda, os níveis de proficiência que permitem medir os progressos dos aprendentes em todas as etapas da aprendizagem. A natureza taxonômica do Cadre representa "uma tentativa de abordagem da enorme complexidade da linguagem humana, analisando a competência em língua nas suas diferentes componentes" (CONSEIL DE L'EUROPE, 2001, p. 9).

As competências de comunicação em francês, preconizadas para o DELF A2, para o nível pretendido pelos aprendizes, de acordo com o Cadre européen commun de référence pour les langues (CONSEIL DE L'EUROPE, 2001), são:

- Competências de compreensão e de produção orais: Compreender expressões e palavras-chave ligadas ao seu cotidiano e entorno imediato para estabelecer uma comunicação e um diálogo com a troca de informações diretas e básicas sobre a família, a escola, os estudos, em situações simples, desde que o discurso seja articulado de forma clara e pausada;

- Competências de compreensão e de produção escritas: Compreender textos simples de uso corrente, como anúncios, folhetos, correspondência curta e simples e escrever notas e mensagens sobre assuntos de necessidade imediata, como um $e$ -

\footnotetext{
${ }^{4}$ Quadro Europeu Comum de Referência para as Línguas: aprendizagem, ensino, avaliação. Conselho da Europa.

${ }^{5}$ No original: "une tentative pour traiter la grande complexité du langage humain en découpant la compétence langagière selon ses différentes composantes".
} 
mail ou outras mensagens igualmente curtas e simples.

Assim, as estratégias aplicadas em sala de aula foram estruturadas, atendendo a esses parâmetros, de modo a privilegiar atividades de compreensão e produção orais, enquanto atividades de compreensão e produção escritas deveriam ser realizadas em casa.

Ficou acordado que as eventuais dúvidas seriam tratadas em sala de aula ou dirigidas por e-mail a um endereço específico que permitiria comunicação direta com a professora/pesquisadora. Presumimos que para tal, os alunos poderiam utilizar o computador da escola ou de casa, o notebook, o tablet e mesmo o smartphone, com seus respectivos editores de texto.

Todas as atividades foram propostas considerando os objetivos previstos e a melhor forma possível de comunicação para cada uma delas, sendo importante compreender quando, como e porque a comunicação síncrona ou assíncrona ${ }^{6}$ influencia a aprendizagem (GUICHON, 2012a)

Desse modo, as atividades assíncronas foram concebidas, observando seu potencial para intensificar a capacidade de tratamento da informação, pela possibilidade do receptor dispor de mais tempo para compreender uma mensagem e preparar sua resposta, conforme argumenta Guichon (2012a). A possibilidade de ler um texto em casa, por exemplo, permite a consulta a um dicionário, o que facilita a compreensão do texto. Além disso, a oportunidade de controlar a escuta de um documento sonoro, via de regra, melhora a compreensão. A produção de textos, quando realizada de forma assíncrona, permite que os estudantes planejem melhor o que precisam escrever ou falar. Isso os leva a ter uma atenção maior à correção linguística e à qualidade textual (GUICHON, 2012a).

Julgamos que a fluência oral é um dos objetivos maiores na aprendizagem de uma língua estrangeira, e que a sincronia comunicacional permite o desenvolvimento das competências discursivas (GUICHON, 2012a, 2012b). Além de atividades presenciais, incluímos meios de comunicação instantânea com objetivo de favorecer o desenvolvimento da comunicação oral.

Nessa perspectiva, optamos por propor, primordialmente, atividades assíncronas para

\footnotetext{
${ }^{6}$ A comunicação síncrona ocorre em um momento específico de modo que os participantes podem se comunicar entre si ou trocar informações de forma simultânea. A comunicação assíncrona ocorre de modo diferido, ou seja, a comunicação em tempos distintos. (CORTÊS; GABRIEL; MARTINS, 2010).
} 
as tarefas de compreensão e produção escritas, não apenas pela flexibilidade do tempo disponível, como também em função da escolha de outros recursos para sua realização. Para as atividades de compreensão e produção orais, foram priorizadas atividades síncronas, que permitem dar retorno imediato das dúvidas e realizar observações sobre o desempenho dos estudantes.

Para os textos escritos, foi aceita a proposta de utilização do Google Drive, o que permitiria a inserção das produções desenvolvidas pelos alunos, em pastas criadas com o nome de cada um deles. Durante todo o período de aulas, eles foram provocados a revisar os documentos produzidos e a compartilhar ideias por intermédio da edição colaborativa dos textos. Além disso, a turma poderia esclarecer dúvidas, por $e$-mail.

Ao todo, foram indicadas treze tarefas para produção escrita. Essas tarefas passariam por cinco etapas: (1) envio do texto, (2) recebimento da revisão da professora, (3) devolução da revisão para realização dos ajustes pelos estudantes, (4) devolução do texto ajustado à professora e (5) informe final com a avaliação expressa numericamente pela professora.

Importante ressaltar que nesse processo, o estudante tinha a oportunidade de revisar sua produção até que o texto estivesse coeso, coerente e com grau de acurácia equivalente ao seu estágio de desenvolvimento de aprendizagem.

Abaixo, listamos os temas propostos, na ordem em que foram apresentados aos alunos. Observe-se que dois temas foram reapresentados e que mostramos, entre parênteses, quantos, dentre os dezesseis alunos, realizaram as tarefas: apresentação pessoal (15); melhor amigo/a (12); relato sobre a rotina (13); diálogo em uma loja (10), carta a um/a amigo/a (9); entrevista (12); carta formal (6); apresentação da família (5); texto sobre profissões (5); apresentação pessoal (4); relato sobre a rotina (4); relato de um filme (7) e uma produção livre (4).

Os estudantes que usavam o e-mail com maior frequência, cumpriram as tarefas com regularidade. Aqueles que pouco o utilizavam enviaram um número reduzido de produções escritas. Alguns relataram pouca ou nenhuma habilidade para usar o Google Drive e lhes foi proposto que entregassem os textos em papel, digitados ou manuscritos.

É interessante observar que a faixa etária dos alunos condiz com aquela dos "nativos digitais", termo cunhado por Prensky (2001), pela presumida facilidade com que utilizam os aparatos tecnológicos. Entretanto, de fato, isso não parece corresponder à realidade. Esse engajamento dos "nativos digitais", geralmente, fica aquém da expectativa, como foi possível 
observar no decorrer das aulas. Contudo, essa denominação fez com que as gerações anteriores, nas quais incluem-se os professores, sentissem-se inibidas no uso dos aparatos tecnológicos (LIVINSTONE, 2009; SELWYN, 2011, 2013). Cabe igualmente ressaltar que embora o termo permaneça sendo utilizado, o próprio Prensky (2012) reviu essa designação, observando que a variação na destreza do uso desses aparatos dá-se em função das habilidades pessoais. Desta forma, ele cunhou o termo, mais apropriado a nosso ver, "sabedoria digital".

Durante todo o período de aulas, a professora/pesquisadora contou com o apoio dos estudantes que tinham facilidade e auxiliavam seus colegas, em tempos vagos da turma, a usar o Google Drive e outros recursos digitais. Ao mesmo tempo, aqueles que dominavam maior vocabulário e as estruturas do francês, por exemplo, auxiliavam os colegas. Enfim, todos ajudavam-se mutuamente para organizar seus estudos, seguindo uma prática solidária, identificada como uma característica comum aos integrantes da turma.

Dessa maneira, o trabalho foi desenvolvido considerando-se que a habilidade de trabalhar colaborativamente auxilia os estudantes a conhecer mais, a fazer melhor, a conviver, o que facilitou o desenvolvimento das habilidades de pensamento de ordem superior e a aprendizagem em si (CHURCHES, 2009).

Importante observar que, em geral, crianças e jovens, sobretudo em parceria com colegas, desenvolvem com facilidade habilidades para utilizar as tecnologias digitais, especialmente as relacionadas à comunicação interpessoal. Entretanto, é percebida certa dificuldade dos estudantes "em transitar entre a aprendizagem construída no uso de tecnologias digitais e a aprendizagem escolar" (BANNELL et alii., 2016, p. 70).

As produções escritas eram corrigidas, pelos os estudantes, segundo os critérios do Cadre, em conjunto com a professora/pesquisadora, devidamente habilitada para correção dos exames DELF dos níveis A1, A2, B1 e B2, pela instituição particular de ensino de francês, responsável pela organização dos exames DELF no Rio de Janeiro. Desse modo, os estudantes, ao cumprirem as etapas fixadas, puderam avaliar qualitativa e quantitativamente suas produções escritas.

De fato, os recursos digitais propostos dentro de uma lógica de compartilhamento e de trocas virtuais puderam trazer um avanço na aprendizagem de línguas, de acordo com o que é apontado por Lancien (1998), entretanto, no âmbito da nossa pesquisa, nossa expectativa era a 
de uma interação mais contínua e mais comum a todos do grupo.

O correio eletrônico e o Google Drive - para o envio dos textos, a revisão compartilhada com a professora/pesquisadora, a troca de mensagens para o esclarecimento de dúvidas e a finalização de cada tarefa, não foram utilizados por todos com a frequência delineada para o desenvolvimento das atividades. A interação para o desenvolvimento da produção escrita foi menor do que a esperada, quando correlacionamos o número de alunos e a quantidade de interações virtuais voltadas para seu aprimoramento.

Para a produção oral, a sequência dos temas propostos, alguns deles duplicados, acompanhados da indicação do número de alunos que os desenvolveram foi: apresentação pessoal (2); relato sobre a rotina (6); diálogo em uma loja (16); entrevista (16); descrição do/da melhor amigo/a (1); apresentação da família (1); relato de um filme (2); relato sobre a rotina (3); texto sobre profissões (1); carta a um/a amigo/a (1).

O grupo de estudantes, diante de seu objetivo de ampliar o desenvolvimento da competência de produção oral, assumiu o compromisso de participar ativamente das atividades propostas. Entretanto, a produção oral, fora da sala de aula, ficou abaixo do quantitativo previsto.

Para as atividades de produção oral, a professora/pesquisadora incentivou os estudantes a criar e enviar podcasts, com os temas sugeridos, a partir do Spreaker ${ }^{7}$. Observando que o uso daquele aplicativo não era de interesse de todos, a professora/pesquisadora propôs o envio de áudios gravados no próprio smartphone. Os alunos poderiam ler textos, falar sobre um tema sem ler, enviar áudios sem qualquer correção, pois o objetivo era praticar a produção oral. Planejamos essa proposta para alcançar os objetivos planejados, segundo o que nossas concepções profissionais indicavam ser melhor para o grupo de estudantes, como sublinha Tripp (2005). Em educação, diz o autor, o pesquisador visa contribuir para o desenvolvimento dos estudantes de forma que as mudanças possam melhorar a aprendizagem e aumentar o interesse, por exemplo.

Para o desenvolvimento da compreensão oral, vários exercícios foram propostos em sala. A avaliação do desempenho de cada um era realizada pela professora/pesquisadora juntamente com os próprios estudantes. Todo o grupo percebeu que era preciso intensificar os

\footnotetext{
${ }^{7}$ O Spreaker é um aplicativo que disponibiliza ferramentas para criação e disponibilização de podcasts. Disponível em: $<$ https://www.spreaker.com/>
} 
estudos. Assim, os estudantes reconheciam suas dificuldades e o grupo planejou algumas ações como: assistir filmes de curta e longa metragem, ouvir e cantar músicas em francês, bem como o uso do aplicativo Français authentiqu ${ }^{8}$. Por iniciativa própria, no grupo do WhatsApp, alguns alunos enviavam links de clipes musicais reforçando o uso desse aplicativo e as práticas solidárias.

As redes sociais digitais podem trazer diferentes possibilidades para a construção do conhecimento (KENSKI, 2012), pois, como observamos, elas conectaram os participantes e facilitaram o aprendizado em conjunto e o apoio mútuo de modo abrangente, em diferentes tempos e espaços.

Lembramos que a professora/pesquisadora procurou, nas entrevistas individuais semiestruturadas, ampliar os dados para a investigação. Encontramos testemunho da aprendizagem colaborativa acima referenciada no relato abaixo:

Quando eu fui estudar para o exame A2, a gente trocou áudio. À noite todo mundo o tempo todo, eu tava lá no WhatsApp, aí escuta de novo, não é isso, aí você manda áudio de novo, todo mundo, pessoal do DELF da tarde e eu tenho os amigos do DELF da manhã também, aí eles mandavam alguma coisa, não o professor falou que não é assim, é desse jeito. (Aluno 3)

Os alunos que trocaram áudios em francês, por meio do WhatsApp, relataram ter percebido uma melhora na produção oral. Aqui recordamos que a aprendizagem e o ensino de um idioma não devem estar baseados somente em livros didáticos e na pronúncia do professor, conforme aponta Kenski (2012).

Nas entrevistas, indagamos se os alunos observaram alguma melhora na sua produção oral. As respostas foram positivas, como por exemplo: “Eu acho que ocorreu uma melhora. É importante você se ouvir porque você tem mais confiança ou vê se tá certo, essas coisas. (Aluno 5). Outro estudante considerou o aplicativo Spreaker tão interessante a ponto de também utilizá-lo para o aprimoramento do inglês: "Usei bastante pra estudar pra prova oral (...) É bom ouvir! Tanto que daí, quando eu fui estudar pra produção oral, eu não ficava pensando no que eu ia falar. Eu usei [o Spreaker] pro inglês!’'(Aluno 15)

As respostas acima, nos fazem crer que a tecnologia pode ativar determinadas potencialidades, entretanto "a informação está no domínio pessoal do usuário - é ele quem define se a informação acessada acrescenta algum valor ao estado anterior, estabelecendo

\footnotetext{
${ }^{8}$ Français authentique é um site que disponibiliza uma série de recursos que contribuem para a aprendizagem do francês. Disponível em: <https://www.francaisauthentique.com/>
} 
significado e modificando atitudes" (BANNELL et alii., 2016, p. 104).

Conforme apresentamos, o Cadre dá ênfase ao papel da interação na aprendizagem e uso de uma língua em que, nos atos de fala, cada interlocutor aprende a ouvir e a preparar sua resposta. Melhor dizendo, os estudantes puderam se comunicar em francês, no nível equivalente aos seus estudos, a partir de discussões sobre temas de seu cotidiano. Lançando mão das habilidades de pensamento e das competências já internalizadas, foram incentivados a aprofundar seus conhecimentos para elaborar as tarefas em níveis mais complexos de comunicação e interação em francês.

Segundo Bannell et alii. (2016), os efeitos cognitivos com uso de artefatos tecnológicos surgem quando determinadas funções intelectuais são transpostas para o uso do artefato tecnológico. Neste caso configura-se uma divisão das tarefas e, consequentemente, uma interdependência entre o utilizador e o artefato. Essa parceria ocorre tanto no uso da calculadora digital e do editor de texto, quanto no uso do ábaco, do livro e do lápis, por exemplo. Assim, é necessário ressaltar que são as atividades realizadas com uso da tecnologia que afetam a cognição, não a tecnologia por si só. As tecnologias são produtos de necessidades culturais, e por meio "do desenvolvimento e da implantação de artefatos que encarnaram intenções e desejos, os seres humanos obtêm ingerência sobre suas necessidades" (BANNELL et alii., 2016, p. 67).

Entendemos que as atividades de aprendizagem podem ser realizadas sem determinada tecnologia, mas seu uso pode contribuir de maneira significativa para o desempenho cognitivo, conforme reportamos abaixo o relato de um entrevistado, a respeito do uso do Spreaker:

Fiz gravações em casa e no colégio, com o tablet e com o smartphone. É até mais fácil porque às vezes você fala (...) na frente do espelho, né? Geralmente, pra decorar alguma coisa e aí não sei, você não escuta direito, se você tá errando alguma coisa. Porque gravar e se ouvir depois parece que você tá ouvindo outra pessoa, sabe? Você escuta e parece que você entende melhor. De repente, se eu fizesse, ou fizer isso com alguma matéria da escola, sei lá, de ler um parágrafo de um livro que eu não tenha entendido muito bem e ficar ouvindo isso, de repente até melhore meu aprendizado, mas eu nunca usei pra isso. (Aluno 12)

Nas palavras do aluno, identificamos sua capacidade de comparar diferentes estratégias para melhorar sua performance em atividades escolares. Ele percebeu que gravar e ouvir a própria voz era mais proveitoso do que falar na frente do espelho e cogitou adotar a 
mesma estratégia para outras disciplinas.

Os efeitos cognitivos obtidos com uso de artefatos tecnológicos são aqueles que transformam de maneira praticamente definitiva as formas de proceder. Se a qualidade da atividade realizada com determinado recurso tecnológico é significativa, dificilmente o aluno deixará de utilizá-lo permanentemente. Neste sentido, o relato de um estudante nos chamou a atenção em relação ao uso do gravador de voz:

Foi bem interessante (...) eu nunca pensei em usar essa plataforma de áudio da forma que eu usei (...) isso me ajudou na produção oral, no exame oral porque eu não tava robotizado, eu não gravava uma fala, eu simplesmente imaginava o que eu falaria e na hora eu usava as estruturas e falava com naturalidade. (Aluno 7)

Sobre o uso do gravador e sua experiência, podemos relacioná-la às ideias de Coll e Monereo (2010) e Bannell et alii. (2016) acerca das percepções sensório-motoras que são experimentadas nos ambientes virtuais em que as simulações se tornam muito próximas do mundo real. Desse modo, em certas situações, a pessoa age com a tecnologia como se ela não existisse, tamanha é a intensidade de sua ação. O sujeito realiza suas intenções, monitora suas atividades e muda suas ações, por meio da tecnologia, de maneira que sua experiência seja ainda mais intensa e real. O testemunho abaixo é um exemplo claro disto:

Embora não estivesse frente a frente com você, pra quem eu mandava o áudio, havia sensação de realidade assim da produção oral porque, não sei como eu posso explicar, parecia que era ao vivo entende? Eu não poderia apagar o que eu falei e colocar o certo de novo. (...) Eu achei que, se no exame eu vou estar com o examinador e o que eu falar eu não posso apagar, trocar e mudar, então quando eu fizer o exercício de mandar pra professora eu também vou procurar ser o mais real possível. (Aluno 6)

A intenção desse aluno foi simular uma conversa real, o que tornou mais significativo seu processo de aprendizagem. Entendemos que ele encontrou um sentido maior para a tarefa, ao invés de simplesmente realizá-la, lendo um texto da forma mais correta possível.

\section{Considerações finais}

Concluímos, recordando dois pontos: (1) o objetivo do artigo é apresentar parte dos resultados de uma pesquisa-ação que teve como foco o desenvolvimento das competências 
comunicativas em francês, a partir do uso das Tecnologias de Informação e Comunicação, por dezesseis estudantes do Ensino Médio de uma escola pública federal da cidade do Rio de Janeiro e (2) ao longo de um ano letivo, o estudo foi realizado durante as aulas de uma professora de francês, sendo ela própria a professora/pesquisadora.

Acompanhando o processo evolutivo da turma, do ponto de vista da fluência, da acurácia, da comunicação e da interação em francês, identificamos o progresso dos estudantes pelas produções escritas e orais, durante o ano letivo, e pela aprovação de todos nos exames DELF Scolaire A2.

Sem dúvida a inclusão de outros recursos tecnológicos contribuíram para que todos alcançassem a aprovação nos exames realizados. Cabe lembrar que nosso trabalho foi desenvolvido levando-se em consideração a lógica da apropriação e não a lógica da imposição, conforme as apresenta Guichon (2012b). Os estudantes foram se apropriando das tecnologias na medida de suas necessidades e interesses. Também puderam, eles próprios, constatar as possibilidades de desenvolvimento de suas habilidades digitais e comunicacionais em francês. Teria sido totalmente descabido impor o uso de recursos tecnológicos digitais tanto quanto impor a utilização de qualquer outra tecnologia como um livro, uma apostila ou quaisquer recursos que desconsiderassem o contexto educacional.

Conforme dissemos anteriormente, em geral, a turma restringiu-se a apresentar as produções escritas, dando prova da realização, sem cuidar da revisão de texto junto com a professora/pesquisadora. Esse comportamento não pode ser generalizado, pois alguns alunos compreenderam o sentido da revisão de cada produção, aprimorando sua produção escrita.

Propor aos estudantes um menor número de atividades e deixar claro que o foco deve estar na qualidade das produções e no tempo investido para um ganho qualitativo, nos parecem ser estratégias mais adequadas. Essas estratégias poderão viabilizar mudanças que tornem os estudantes mais responsáveis em relação aos próprios objetivos educacionais, segundo seus interesses de aprimoramento.

Durante todo o percurso da pesquisa foi possível integrar os recursos digitais móveis às práticas discentes e docentes e constatar que eles podem, efetivamente, melhorar o desenvolvimento da cognição, da interação, da colaboração. Na prática, constatamos que a utilização dos dispositivos digitais potencializou o interesse do grupo e que sua contribuição para a aprendizagem ocorre quando seu uso é dimensionado dentro de condições adequadas 
de acesso e de adaptação ao contexto.

Finalizando, sublinhamos que consideramos que nossa pesquisa-ação alcançou bons resultados ao relacionar práticas de ensino-aprendizagem mediadas por tecnologias, com ênfase na utilização de tecnologias digitais móveis, para o desenvolvimento de competências comunicativas em francês. Contudo, não se pretende generalizar os resultados apresentados, mas sim contribuir de alguma forma para a reflexão e incorporação de tecnologias em processos educacionais. Desse modo, esperamos que as lacunas deste trabalho possam ser complementadas por outras investigações.

\section{REFERÊNCIAS}

ALCANTARA, Claudia Benages. Internet e autonomia na aprendizagem do francês língua estrangeira em meio universitário: a experiência com a plataforma COL. 2006. 100f. Dissertação. (Mestrado em Língua e Literatura Francesa). Faculdade de Filosofia Letras e Ciências Humanas. Universidade de São Paulo. São Paulo. 2006. Disponível em:

$<$ http://www.teses.usp.br/teses/disponiveis/8/8146/tde-27062011-125029/en.php>. Acesso em: 29 fev. 2020.

ALVES-MAZZOTTI, Alda Judith. O planejamento de pesquisas qualitativas. In: ALVESMAZZOTTI, A. J.; GEWANDSZNAJDER, Fernando. O Método nas ciências naturais e sociais: pesquisa quantitativa e qualitativa. 2. ed. São Paulo: Pioneira, 2004.

ARAUJO, Monique da Silva de; FARIA, Daniela Punaro Baratta; PEDROSA, Stella Maria Peixoto de Azevedo. Tecnologias de informação e comunicação na formação docente: subsídios para uma reflexão. In: IV Encontro de iniciação à docência da UEPB, $4^{\circ}$; Encontro de formação de professores da educação básica, 2º 2014, Campina Grande. Anais ENID / UEPB. Realize, v. 1. Campina Grande: UEPB, 2014. Disponível em:

<http://www.editorarealize.com.br/revistas/eniduepb/trabalhos/Modalidade_1datahora_04_11 _2014_01_15_32_idinscrito_1180_355bebb73b8c49838d1dac934895921d.pdf>. Acesso em: 22 fev. 2020.

BANNELL, Ralph. et alii. Educação no século XXI: cognição, tecnologias e aprendizagens. Petrópolis: Vozes. Rio de Janeiro: Editora PUC, 2016.

BARDIN, Laurence. Análise de Conteúdo. Lisboa, Portugal: Edições 70, LDA, 1977.

BRASIL. Parâmetros curriculares nacionais: terceiro e quarto ciclos do Ensino Fundamental. MEC, SEF. Brasília, DF. 1998. Disponível em:

<http://cptstatic.s3.amazonaws.com/pdf/cpt/pcn/volume-09-lingua-estrangeira.pdf>. Acesso em: 27 fev. 2020.

CHURCHES, Andrew. Taxonomia de Bloom para la era digital. Disponível em: <http://www.eduteka.org/TaxonomiaBloomDigital.php>. Acesso em: 24 fev. 2020. 
COLL, César; MONEREO, Carles. Apresentação. In: COLL, César; MONEREO, Carles. (Org.). Psicologia da educação virtual: aprender e ensinar com as tecnologias da informação e da comunicação. Porto Alegre: Artmed, 2010, p. 9-12.

CONSEIL DE L'EUROPE. Cadre européen commun de référence pour les langues: apprendre, enseigner, evaluer, 2001. Disponível em: 〈https://rm.coe.int/16802fc3a8>. Acesso em: 27 fev. 2020.

CORTÊS, Cristina; GABRIEL, Graça; MARTINS, Ana Bela. SBIDM: comunicação síncrona, assíncrona e multidireccional. $10^{\circ}$ Congresso Nacional de Bibliotecários, Arquivistas e Documentalistas. Guimarães, Portugal, 2010. Anais $10^{\circ}$ CNBAD. Disponível em:

$<$ https://www.bad.pt/publicacoes/index.php/congressosbad/article/view/209/205>. Acesso em: 12 jun. 2020.

FELICETTI, Vera Lucia; MOROSINI, Marília Costa. Do compromisso ao comprometimento: o estudante e a aprendizagem. Educar em Revista. Curitiba: Editora UFPR, n. especial, p. 23-44, 2010. Disponível em:

<http://www.scielo.br/pdf/er/nspe2/02.pdf>. Acesso em: 1 mar. 2015.

FRANGO, Florência Roballo Basílio. Desenvolvimento da competência comunicativa: a oralidade do francês com as TIC. 2012. 96f. Dissertação. (Mestrado em Ensino de Francês e de Inglês). Escola Superior de Educação. Instituto Politécnico Castelo Branco. Lisboa. Disponível em:

<http://repositorio.ipcb.pt/bitstream/10400.11/1540/3/Tese\%20Flor\%C3\%AAncia.pdf>. Acesso em: 22 fev. 2020.

GUICHON, Nicolas. Vers l'intégration des TIC dans l'enseignement des langues. Paris: Les éditions. Didier, 2012a.

GUICHON, Nicolas. Les usages des TIC par les lycéens: déconnexion entre usages personnels et usages scolaires. Revue Sticef.org, v. 9, 2012b. Disponível em: $<$ https://www.researchgate.net/publication/232709195_Les_usages_des_TIC_par_les_lyceens _-deconnexion_entre_usages_personnels_et_usages_scolaires>. Acesso em: 22 fev. 2020.

KENSKI, Vani Moreira. Educação e tecnologias: o novo ritmo da informação. Campinas, SP: Papirus Editora, 2012.

LANCIEN, Thierry. Le multimédia. Paris: CLE International, 1998.

LÉVY, Pierre. Cibercultura. São Paulo: Editora 34, 1999.

LIVINGSTONE, Sonia. Children and the Internet: Great Expectations, Challenging Realities. Cambridge: Polity Press, 2009.

MOREIRA, Herivelto; CALEFFE, Luiz Gonzaga. Metodologia da pesquisa para o professor pesquisador. Nova Iguaçu, RJ: Lamparina Editora, 2008. 
PRENSKY, Marc. Digital Native, digital immmigrants. Digital Native immigrants. On the horizon. MCB University Press, V. 9, N.5, October, 2001.Disponívelem:

<http://www.marcprensky.com/writing/Prensky\%20-\%20Digital\%20Natives,\%20Digital\%20 Immigrants\%20-\%20Part1.pdf> Acesso em: 29 mar. 2020.

PRENSKY, Marc. From Digital Natives to Digital Wisdom. Introduction in From Digital Natives to Digital Wisdom: Hopeful Essays for 21st Century Education. Corwin: 2012. Disponível em:

<http://www.marcprensky.com/writing/Prensky-Intro_to_From_DN_to_DW.pdf> Acesso em: 29 mar. 2020.

SCHÖN, Donald Alan. Educando o Profissional Reflexivo: um novo design para o ensino e a aprendizagem. Trad.Roberto Cataldo Costa. Porto Alegre: Artmed, 2000.

SELWYN, Neil. The digital native: Mith and reality, Aslib Proceedings 61.4 (2011) p. 264379.

SELWYN, Neil. Entretien. Technologie numérique et l'université contemporaine : aspects de recherche. Distances e Médiations des Savoirs (DMS). n.4, 2013. Disponível em:

<https://journals.openedition.org/dms/369>. Acesso em: 22 fev. 2020.

TRIPP, David. Pesquisa-ação: uma introdução metodológica. Educação e Pesquisa. São Paulo, v. 31, n. 3, p. 443-466, set./dez. 2005. Disponível em:

<http://w0ww.scielo.br/pdf/ep/v31n3/a09v31n3.pdf>. Acesso em: 22 fev. 2020.

Recebido em 06/03. Aceito em 18/06. 